\title{
THE
}

2014

\section{Self-Control and Adverse “Drinking” Consequences}

\author{
Barbara J. Costello \\ University of Rhode Island, costello@uri.edu \\ Bradley J. Anderson \\ Michael D. Stein
}

Follow this and additional works at: https://digitalcommons.uri.edu/soc_facpubs

The University of Rhode Island Faculty have made this article openly available.

Please let us know how Open Access to this research benefits you.

This is a pre-publication author manuscript of the final, published article.

Terms of Use

This article is made available under the terms and conditions applicable towards Open Access

Policy Articles, as set forth in our Terms of Use.

\section{Citation/Publisher Attribution}

Barbara J. Costello, Bradley J. Anderson \& Michael D. Stein (2014) Self-Control and Adverse "Drinking" Consequences, Deviant Behavior, 35:12, 973-992, DOI: 10.1080/01639625.2014.901075

Available at: http://dx.doi.org/ 10.1080/01639625.2014.901075

This Article is brought to you for free and open access by the Sociology \& Anthropology at DigitalCommons@URI. It has been accepted for inclusion in Sociology \& Anthropology Faculty Publications by an authorized administrator of DigitalCommons@URI. For more information, please contact digitalcommons-group@uri.edu. 
Self-Control and Adverse "Drinking" Consequences

February, 2014

\author{
Barbara J. Costello, Ph.D.* \\ University of Rhode Island, Department of Sociology and Anthropology
}

Bradley J. Anderson, Ph.D.

Butler Hospital, General Medicine Research

Michael D. Stein, M.D.

Butler Hospital, General Medicine Research

*Corresponding Author. Contact: Costello@ uri.edu, University of Rhode Island, Department of Sociology and Anthropology, Chafee Hall, Kingston, RI 02881, (401) 874-2877. 


\title{
SELF-CONTROL AND ADVERSE “DRINKING" CONSEQUENCES
}

\begin{abstract}
There is a well-established correlation between alcohol use and a variety of negative outcomes that are apparently direct consequences of alcohol use. These include health problems, problems with relationships, work, and money, criminal behavior, and crime victimization. Most of the research on these adverse consequences in the literature on alcohol use and abuse focuses only on alcohol use itself as a cause of these outcomes. However, Gottfredson and Hirschi's (1990) selfcontrol theory holds that alcohol use and these negative outcomes are likely to have a common cause - low self-control. In this study we test the hypothesis that low self-control is an important predictor of adverse drinking consequences after controlling for alcohol dependence and for frequency and quantity of alcohol use. Using a sample of 190 incarcerated women with hazardous levels of alcohol use, we find that self-control predicts negative drinking consequences better than the combined measures of alcohol dependence, frequency and quantity of drinking, and a frequency by quantity interaction effect. Consistent with Gottfredson and Hirschi's arguments, these findings suggests that various forms of risk-taking behavior and negative outcomes can be conceptualized as indicators of underlying levels of self-control rather than unique problems requiring unique treatment and prevention efforts.
\end{abstract}


Research on Gottfredson and Hirschi's (1990) self-control theory has shown self-control to be a robust predictor of a wide range of criminal and analogous behaviors. The theory has been tested in dozens of different countries (e.g., Rebellon, Straus, and Medeiros, 2008), with different demographic groups within the U.S. (e.g., Vazsonyi and Crosswhite, 2004), and with large, nationally representative samples as well as small convenience samples of groups expected to be quite different in their levels of self-control, such as college students (e.g. Gibbs, Giever, and Martin, 1998) and incarcerated offenders (De Li, 2005). The body of research on self-control theory has led to the conclusion that "self-control is one of the strongest known predictors of crime" (Hay and Forrest, 2008: 1039).

One of Gottfredson and Hirschi's major claims about the theory's generality has not had as much impact on research in criminology and related fields, and that is their claim of versatility in offending and in behaviors analogous to crime. Research has shown that offenders tend not to specialize, and there is widespread recognition that self-control can explain noncriminal behaviors such as alcohol and drug use, accidents, and other forms of risk-taking. However, it is still common to find studies that separate crimes into types such as violent crime, property crime, or substance use and to run separate analyses for each. It is also the case that the study of various forms of deviant behaviors is compartmentalized into different disciplines, with researchers having increasingly narrow areas of specialization (Junger and Dekovic, 2003).

Gottfredson and Hirschi were clear in their position on such compartmentalization. They state, "In our view, the common element in crime, deviant behavior, sin, and accident is so overriding that the tendency to treat them as distinct phenomena subject to distinct causes is one of the major intellectual errors of positive thought and is a major cost of the tendency to divide intellectual problems among academic disciplines" (1990: 10). Essentially, Gottfredson and Hirschi argue that 
different types of deviant behaviors are correlated only because they are common outcomes of low self-control, and thus that these correlations are spurious. In this paper, we evaluate the ability of low self-control to explain negative outcomes that are widely assumed in the literature on alcohol abuse to be caused by heavy alcohol consumption itself, or "adverse alcohol consequences." We argue that many of the apparent negative outcomes of alcohol use are, in fact, the result of low self-control rather than, or in addition to, alcohol use itself, and that research on alcohol and drug use could be significantly improved with the inclusion of self-control as a predictor of negative outcomes.

\section{SELF-CONTROL THEORY}

Gottfredson and Hirschi (1990) argue that the major cause of crime and behavior analogous to crime is low self-control. They conceptualize self-control as a relatively stable individual characteristic that is acquired through the process of early childhood socialization. Gottfredson and Hirschi (1990) hold that humans by nature tend to engage in behaviors that provide immediate gratification, and that self-control, or the ability to defer gratification, must be learned. Children who

are consistently supervised and corrected for misbehavior will develop higher levels of self-control, or a general tendency to consider the consequences of their acts before engaging in them. In contrast, children who are not well socialized in early childhood will tend to be impulsive, short-sighted, unable to work toward distant goals, and lacking skills or abilities that require extended periods of training or practice. Once established, individual differences in self-control tend to remain stable across the life course (Gottfredson and Hirschi, 1990).

Gottfredson and Hirschi (1990) contend that low self-control is a very general behavioral tendency with a variety of adverse consequences. Criminal offenders tend to exhibit versatility in offending patterns and do not specialize in certain types of crimes (Britt, 1994; Chapple and Hope, 
2003; DeLisi, 2001; Junger and DeKovic, 2003; McGloin, Sullivan, and Piquero, 2009; Osgood et al., 1988). Offenders also tend to engage in acts analogous to crime, which are not crimes per se but which provide immediate gratification and tend to have long-term negative consequences. For example, offenders are more likely to smoke, drink to excess, gamble, engage in risky sexual behaviors, and have higher rates of accidents and illness (Gottfredson and Hirschi, 1990). Even more broadly, Gottfredson and Hirschi contend that low self-control is associated with a reduced ability to succeed in conventional social institutions such as education, the workplace, and marriage and the family because success in such settings requires planning, commitment, and the ability to delay gratification. Thus, individuals with low self-control are expected to do more poorly in school, have less stable employment patterns, and have more problems maintaining social relationships than those with higher levels of self-control.

Gottfredson and Hirschi (1990) thus view low self-control as a cause of a wide variety of negative outcomes. They criticize the study of various forms of "reckless or imprudent" behavior as separate phenomena requiring unique explanations. They are also critical of searching for causal relationships between forms of crime and deviance, arguing instead that the correlations between these behaviors are spurious, the common outcomes of low self-control. As they put it,

This large class of behavior is not systematically incorporated into any modern discipline but is partitioned among problem-oriented researchers in a variety of disciplines. For example, work on the causes of accidents, injuries, and illnesses and on the physical consequences of certain foods, drugs, and activity patterns is carried out by a multitude of researchers without any notion of the common element in these phenomena (Gottfredson and Hirschi, 1990: 10). This common element, according to Gottfredson and Hirschi, is low self-control. 
Much empirical research has supported Gottfredson and Hirschi's theory. The results of their meta-analysis led Pratt and Cullen to conclude that low self-control theory has garnered "fairly impressive empirical support" (2000: 951). Research subsequent to this meta-analysis has continued to find low self-control to be a robust predictor of crime and a wide variety of acts analogous to crime (Hay and Forrest, 2008). Examples of analogous acts found to be related to low self-control include software piracy (Higgins, 2004), binge or heavy episodic drinking (Costello, Anderson, and Stein, 2006; Gibson, Schreck, and Miller, 2004; Piquero, Gibson, and Tibbets, 2002), illicit sexual behavior (Love, 2006), gambling (Evans et al., 1997), employee theft (Langton, Piquero, and Hollinger, 2006), academic dishonesty (Cochran et al., 1998), school absenteeism (Gibbs and Giever, 1995), and drinking and driving (Piquero and Tibbetts, 1996). Evans et al. (1997) examined the effect of selfcontrol on a broad range of social consequences; they found that low self-control was associated with lower quality relationships with friends and family, lower educational attainment, having more criminal associates, and lower attachment to church. Low self-control may also help explain the robust correlation between conduct disorder and alcohol and other drug use (Pardini, White, and Stouthamer-Loeber, 2007).

\section{SELF-CONTROL, ALCOHOL USE, AND ADVERSE DRINKING CONSEQUENCES}

A number of studies have established the relationship between low self-control, alcohol use, and behaviors associated with alcohol use or abuse. Keane, Maxim, and Teevan (1993) found a negative relationship between behavioral measures of self-control and blood alcohol concentration in a sample of Canadian drivers. Arneklev et al. (1993) found that low self-control was correlated with having more than two or three drinks per week in a sample of adults in an American city. Costello, Anderson, and Stein (2006) found a strong relationship between low self-control and heavy episodic 
(or binge) drinking in a convenience sample of high school students in Fayetteville, Arkansas. Using the Add Health data, Baker (2010) found a significant relationship between low self-control and problematic drinking among adolescents. Wolfe and Higgins (2008) found a relationship between self-control and frequency of drinking among college students. Studies conducted outside the United States have also found significant negative relationships between self-control and alcohol consumption, including a study of college students in Austria (Gerich, 2013), a random sample of Russian adults (Botchkovar and Broidy, 2013), a combined sample including data from youths aged 12-16 years in 25 European countries (Podaná and Buriánek, 2013), and a sample of adolescents in the United States, the Netherlands, Switzerland, and Hungary (Vazsonyi et al., 2001).

Two studies have directly examined the relationship between self-control and negative outcomes of drinking behaviors. Piquero, Gibson, and Tibbetts (2002) analyzed data collected from college freshmen to assess whether low self-control could fully account for the correlation between binge drinking and alcohol-related behaviors. Gibson, Schreck, and Miller (2004) analyzed the same data set, including additional statistical controls for known covariates of binge drinking and testing for interaction effects between binge drinking and alcohol-related behaviors. The data used in both studies focused on binge drinking, measured with a single item asking the respondents how many drinks they consumed during a typical drinking occasion. Students reporting that they did not drink at all were eliminated from the sample, and the remaining students' responses to this question were dichotomized, with those reporting five or more drinks per occasion scored as 1 and 0 otherwise.

Alcohol-related behaviors were measured with eleven questions asking "while drinking alcohol have you ever gotten into trouble with police, been late to school, could have hurt yourself or others, got into fights, missed school or work, had problems with a teacher, had problems with a 
friend, stayed home from school, and hurt chances for a raise or better job" (Gibson, Schreck, and Miller, 2004: 414).

In both studies, the authors found that low self-control was significantly associated with both binge drinking and alcohol-related behavior, but contrary to predictions derived from self-control theory, self-control did not fully explain the correlation between the two. Gibson, Schreck, and Miller (2004) found that binge drinking and peer delinquency were both more important predictors of alcohol-related behavior than self-control was. However, consistent with what self-control theory would predict, self-control was still a significant predictor of alcohol-related behavior with drinking held constant, and interaction effects showed that binge drinking itself was not a significant predictor of alcohol-related behavior among those with extremely high levels of self-control.

A similar study by Ribeaud and Eisner (2006) assessed the ability of self-control to explain the correlation between frequency of drug and alcohol use and delinquency. Using a random sample of youths in the Swiss canton of Zurich, they found that self-control substantially reduces the correlation between substance use and delinquency, consistent with expectations from self-control theory. However, self-control did not completely explain the relationship between substance use and delinquency, which were still significantly related controlling for self-control and each of its conceptual dimensions.

There has been some similar research not explicitly drawing on Gottfredson and Hirschi's concept low self-control but on the related concept of impulsivity. Focusing on sexual risk behaviors as the dependent variable of interest, Hayaki, Anderson, and Stein (2006) examined whether impulsivity, measured with Eysenck's I-7 impulsivity index (Eysenck et al., 1985), could explain the positive correlation between drug use and sexual risk behaviors. They found that impulsivity explained risky sexual behavior after controlling for substance use, and of the drugs examined, only 
cocaine use predicted risky sex once impulsivity was controlled. The authors noted that their research, unlike previous studies, focused on a general trait of impulsivity as opposed to measures of impulsive sexual behavior specifically. Thus their approach in this study was similar to the approach advocated by Gottfredson and Hirschi (1990), taking a more general view of individual differences that predict risky behavior.

Hayaki et al. (2005) similarly found that the Eysenck impulsivity index explained negative life events among substance users beyond the effect of drug use itself. The negative life events measured in the study included accidents, money problems, being arrested or incarcerated, and relationship problems. Hayaki et al. (2005) found that once impulsivity was held constant, there was no relationship between drug use and negative life events. However, their models explained only a modest proportion of the variation in experiencing negative life events with an $\mathrm{R}^{2}$ of only .10 .

\section{ALCOHOL USE AND ADVERSE DRINKING CONSEQUENCES}

The attempt to assess the negative consequences of alcohol use has a long history (e.g., Jellinek, 1946). However, research focused on these negative consequences, and systematic attempts to develop instruments to measure adverse alcohol outcomes began relatively recently. According to Miller, Tonigan, and Longabaugh (1995: v), this lack of attention to negative outcomes of alcohol use was

"... surprising since, from the perspective of society, the family, and the alcoholic, the most troubling feature of heavy drinking is its negative effects on behavior, health, and emotional adjustment. Individuals enter treatments and society pays for services and research on alcoholism because of the direct, disruptive consequences of inappropriate drinking. 
It has been well established that persons who are chronic heavy alcohol users or who engage in acute periods of heavy episodic drinking are at increased risk for a broad range of negative health, economic, legal, and social outcomes. [emphasis added]

As is clear in this statement, and as common sense would lead us to expect, the study of negative consequences of alcohol use has focused on alcohol use itself as the primary, or sole, cause of negative outcomes of alcohol use. Studies of the negative effects of alcohol use find a correlation between alcohol use or binge drinking and health problems, accidents, academic problems among students, injuries and fatalities, assaults, arrests, crime victimization, feeling guilty about drinking, financial problems, relationship problems, and problems related to employment. (D'Amico et al., 2001; Graham et al., 2011; Jones-Webb et al., 1997; Plant et al., 2000; Ramstedt, 2002; Strong et al., 2010; Turrisi et al., 2006; Wyllie, Zhang, and Casswell, 2000).

From our perspective, two major problems in this body of literature are that it is largely atheoretical and that it tends to ignore findings from related disciplines that could situate the study of alcohol consequences in a larger body of research and evidence. Studies of adverse consequences typically draw mostly descriptive conclusions about patterns of experiencing negative consequences. The following findings are typical:

"Drinkers in Ireland drink more than in other western European countries and many have risky drinking habits that lead to adverse consequences." Males in Ireland are more likely to binge drink than females, and both volume of drinking and binge drinking affect the likelihood of adverse consequences. (Ramstedt and Hope, 2005: 273).

"Results revealed higher levels of consumption and more negative drinking consequences for men, more psychological distress symptoms reported by women, and stronger relationships between psychological symptoms and drinking consequences than use per se. The association 
between psychological distress and negative drinking consequences was stronger among men than women. .." (Markman Geisner, Larimer, and Neighbors, 2004: 843).

". . the effect of both positive and negative drinking reasons on alcohol-related problems was partially mediated by alcohol consumption among both secondary-school students and university students. There were different correlates of problematic drinking among younger and older students, which suggest that different types of intervention should be used with the two age groups" (Cox et al., 2006: 2147).

The lack of theoretically-informed research is particularly unfortunate given the large size and scope of many datasets collected to study alcohol consequences. For example, Wyllie, Zhang, and Casswell (2000) compiled data from ten general population random samples to construct a dataset of over 11,000 adults representative of the population in Auckland, New Zealand. They concluded that some alcohol consequences occur only at high volumes of alcohol consumption while others show a more linear relationship with volume consumed. Variables related to other determinants of alcohol consequences were not included in their analysis. Similarly, Graham et al. (2011) analyze data from a dataset collected by the Gender, Alcohol, and Culture: An International Study (GENACIS) collaboration, which included data from 27 countries and around 40,000 respondents. Although the study looked at the effects of some macro-level social context variables in explaining differences in drinking behavior cross-culturally, there were few survey questions included in the survey that measured variables or processes relevant to criminological theory (some exceptions were measures of stress, and measures of behavior analogous to crime such as drug use, gambling, and overeating) (GENACIS website, 2014). This is true even though the study was focused on gender differences in drinking and alcohol consequences, the incidence of violence in interpersonal relationships, and the effects of social inequality and drinking norms on alcohol use and consequences (GENACIS website, 
2014), which are of interest to criminologists. Graham et al. (2011) conclude that men experienced greater alcohol consequences than women, and that negative consequences were greater in countries with high quantity of alcohol consumption, with fewer drinkers, and with lower gross domestic product and human development indices. However, the implications of this study are much more limited than they might have been with the inclusion of additional measures designed to explain some of these patterns, some of which might have been drawn from criminological research.

That having been said, there has been some attention in the alcohol literature to factors other than alcohol use or abuse itself that may be associated with increased risk of adverse drinking consequences. For example, Glassman, Werch, and Jobli (2007) found that adolescents' self-control strategies to avoid alcohol use, such as deliberately avoiding situations in which others are drinking, significantly predicted reduced alcohol use and fewer negative consequences. Benton, Benton, and Downey (2006), using a college student sample, reported that attitudes towards risk behaviors significantly predicted negative drinking consequences after adjusting for students' use of alcohol, gender, and other potential confounds. Peer alcohol use and perceived drinking norms were found to be positively associated with both alcohol consumption and negative drinking consequences (JonesWebb et al., 1997), and the relationship between the two independent variables and negative drinking consequences held when alcohol consumption was controlled.

Although these studies recognize that factors other than alcohol use might be associated with adverse alcohol consequences, we argue that this body of research could be significantly improved by situating its hypotheses and findings in the criminological literature, including research on selfcontrol theory and differential association or learning theories. 


\section{Hypothesis}

Although it would be difficult to argue that adverse alcohol consequences are not caused at least in part by alcohol consumption, Gottfredson and Hirschi's theory leads to the prediction that some of the apparent casual relationship between alcohol use and adverse consequences can be explained by the effects of low self-control. We hypothesize that low self-control is an important predictor of adverse drinking consequences after controlling for frequency of alcohol use, quantity of alcohol use, the first-order quantity by frequency of alcohol use interaction, and meeting clinical criteria for recent diagnosis of alcohol dependence.

\section{DATA AND METHODS}

The present study replicates and extends previous research (Costello, Anderson, and Stein, 2006; Gibson, Schreck, and Miller, 2004; Piquero, Gibson, and Tibbetts, 2002 ) using a sample of incarcerated women who met criteria for hazardous alcohol use in the year prior to assessment. Unlike the adolescent and college student samples used in some prior research (Baker, 2010; Costello, Anderson, and Stein, 2006; Gibson, Schreck, and Miller, 2004), this adult cohort entered the study with hazardous levels of pre-incarceration alcohol use and high risk of adverse drinking consequences. We would also expect this cohort of incarcerated women to exhibit relatively low levels of self-control. While normative standards defining self-control have not been established, Grasmick et al. (1993) presented item means and standard deviations observed on a randomly selected sample of 396 Oklahoma City adults. We used t-tests to compare our observed item means to those reported by Grasmick et al. (1993). Our sample of incarcerated women exhibited significantly $(\mathrm{p}<.05)$ lower self-control on every scale item. Clearly, then, our results cannot be safely generalized to any larger population. At the same time, our sample provides the opportunity to 
test for a relationship between self-control and adverse consequences among a group lower in selfcontrol relative to many samples used in prior research.

Our study also significantly improves upon previous studies due to the quality of measures of alcohol use, including alcohol dependence and both frequency and quantity of drinking. These more detailed measures are able to provide a more definitive test of our hypothesis than previous research that relied on a single dichotomous measure of whether the respondent typically had five or more drinks when he or she consumed alcohol (Gibson, Schreck, and Miller, 2004). We are also able to improve on previous research by controlling for parental alcohol abuse and peer use and support for drinking (Gibson, Schreck, and Miller, 2004; Piquero, Gibson, and Tibbetts, 2002).

We analyzed baseline data collected from incarcerated women enrolled in a randomized clinical trial designed to test the effectiveness of a brief motivational interviewing intervention on post-release alcohol use and HIV risk behaviors (Stein et al., 2010). Participants were recruited from the woman's facility at the Rhode Island Department of Corrections (RI DOC) Adult Correctional Institute (ACI). Because there are no county jails in the geographically small state of Rhode Island, the ACI encompasses all jail, prison, and rehabilitative housing inmates of all levels, including those awaiting arraignment or trial.

Participants were eligible to participate in the study if they were English speaking, planned to reside in Rhode Island for a period of 6 months following release, had engaged in an HIV riskbehavior (engaged in unprotected male-female vaginal or anal sex $\geq 3$ times, or shared drug injection equipment $\geq 3$ times in the 90 days prior to incarceration), and screened positive for hazardous drinking. Hazardous drinking was defined as a score of 8 or higher on the alcohol use disorders identification test, or consuming 4 or more drinks on one occasion 3 or more times in the 90 days prior to incarceration, or consuming an average of 8 or more drinks per week in the 90 days prior to 
incarceration. Of 1,545 participants screened for inclusion in the study, 239 met eligibility criteria, and $190(79.5 \%)$ of the eligible women agreed to participate and completed the baseline assessment. The study protocol and intervention are described more fully in Hebert et al. (2008). All screening and face-to-face interviews were conducted by trained, female research assistants in unmonitored rooms.

\section{Measures}

Adverse alcohol consequences were assessed using a 14-item index asking participants if their use of alcohol had ever caused or contributed to specific negative social consequences. These items are typical of measures used in the literature on alcohol use and adverse alcohol consequences, and the measures reflect the type of difficulties that Gottfredson and Hirschi (1990) hypothesize would be caused by low-self control. Participants were asked about money problems, car accidents, involvement in physical fights, arrests, injuries to self and others, job loss, problems in sexual relationships, relationship and family problems, loss of child custody, and unplanned pregnancy (see Table 4 for item wording.) Internal consistency reliability for the 14 -item summated rating index was .85.

Gottfredson and Hirschi (1990) originally conceptualized self-control as a unidimensional construct encompassing 6 dimensions: impulsivity, being self-centered, preferring simple tasks, riskseeking, preference for physical rather than mental activities, and temper. There has been some controversy over measurement of self-control, particularly with regard to the use of attitudinal measures versus behavioral ones (Gunter and Bakken, 2012; Piquero, 2008). Gottfredson and Hirschi advocate the use of behavioral rather than attitudinal measures of self-control, but problems of tautology can arise depending on the dependent variables of interest in a particular study. In the case 
of the present study, it's clearly problematic to use behavioral measures of self-control such as alcohol use given our interest in distinguishing between self-control and alcohol use as predictors of negative drinking outcomes. In addition, there is evidence that the attitudinal measures originally developed by Grasmick et al. (1993) predict deviance as well as or better than some behavioral measures (Gunter and Bakken, 2012; Pratt and Cullen, 2000).

Thus, in this study we adapt the 24-item attitudinal measure of self-control originally developed by Grasmick et al. (1993). The full scale includes 4 items assessing each of the six elements of self-control described above. Response categories ranged from 1, "strongly disagree," to 4 "strongly agree." Items were recoded so that high scores corresponded with high self-control. Arneklev et al. (1993) and Grasmick et al. (1993) have argued the items represent a single underlying construct. Others have dropped selected items based on factor loadings (e.g., Love, 2006), and Cochran et al. (1998) reported that the items representing the preference for physical rather than mental activities did not fit well with the scale. Nagin and Paternoster (1993) argued that treating the index as a single dimensional measure was appropriate when testing hypotheses derived from selfcontrol theory.

We used principal components factor analysis and item analysis to explore the psychometric properties of the index. We considered multiple criteria in determining the number of factors to retain. Consistent with previous research (Grasmick et al., 1993; DeLisi, Hochstetler, and Murphy, 2003) six principal components had eigenvalues greater than 1.0. However, also consistent with previous research, an examination of the scree plot suggested retaining a single factor. Monte Carlo simulations (Zwick \& Velicer, 1986) have generally found Horn's (1965) parallel analysis and Velicer's minimum average partial (Velicer, 1976) to be the best criteria for determining the number 
of components to retain. Both criteria suggested a one factor solution (see Appendix 1 for item wording and factor loadings.)

Based on initial factor loadings and an examination of item-total statistics and effect on internal-consistency reliability, 6 items were deleted from the final index. Factor loadings for the final 18 items all exceeded .40 and internal consistency reliability of the final 18 -item self-control index was .88. We also note that while internal consistency reliability for the full 24-item index was slightly lower (Cronbach's $\alpha=.869$ ), analyses using the full index generated results that were substantively and statistically consistent with those we report here.

There is substantial evidence for a correlation between peer deviance and deviance (Pratt and Cullen, 2000), and specifically for a correlation between peer alcohol use and alcohol use (Baker, 2010; Gibson, Schreck, and Miller, 2004) For this reason, we include in our analyses a three-item index assessing peer support for drinking. The items were "how many of the people you spend time with have an alcohol or drug problem," "how many of the people you spend time with would support your sobriety or abstinence or efforts to reduce your alcohol use" (reverse coded), and "how many of the people you spend time with encourage your drinking?" Items were scored on a 5 point scale $(0=$ none, $1=$ some, 2 = half, $3=$ most, $4=$ all).

Drinking frequency and quantity were assessed using a 90-day time-line-follow-back method (TLFB) (Sobell \& Sobell, 1992). The TLFB is a very widely used measure of substance use in the drug and alcohol use literature. Participants are prompted to remember important dates, such as birthdays, anniversaries, and holidays, which are marked on a calendar. Using the calendar as a memory aid, they are then asked to recall days they consumed alcohol and the number of drinks consumed. The method has been shown to have good psychometric properties in a range of populations (Sobell et al., 2001). Days on which participants reported being institutionalized were 
excluded from the calculation of summary measures. After so doing, the number of observed TLFB days ranged from 77 to $90 ; 32(16.8 \%)$ of the participants reported at least one night in an institutionalized setting during the 90 day assessment period.

Some studies estimating the effects of alcohol use on adverse alcohol-related consequences have used separate indicators of total volume of alcohol consumed and frequency of heavy episodic or binge drinking (Wyllie et al., 2000; Plant et al., 2000). The National Institute on Alcohol Abuse and Alcoholism National Advisory Council proposed a definition of binge drinking for women of consuming 4 or more drinks in a 2 hour period (NIAAA, 2004). Many studies have operationalized binge drinking as consuming 5 or more drinks per occasion or per day (c.f., Midanik, et al., 1996; Wechsler \& Wuethrich, 2002; Gibson, Schreck, and Miller, 2004; Costello, Anderson, and Stein, 2006) regardless of gender. Our summary measure of drinking frequency was the proportion of days using alcohol; quantity was assessed using as the mean number of drinks per drinking day. This measure has the advantage of not truncating total number of drinks consumed at four or more or five or more, and thus provides a better measure of quantity especially for a population with high rates of problem drinking.

\section{Analysis}

Exploratory analysis using loess regression (locally weighted scatterplot smoothing) indicated that a log transformation helped to linearize (and strengthen) the relationship between adverse alcohol consequences and mean drinks per drinking day. To maximize the estimated effect of alcohol consumption on adverse alcohol consequences we include the first order proportion of days using alcohol by mean drinks per drinking day interaction in some multivariate models; this gives an indication of total volume of alcohol consumed during the period assessed by the TLFB. The 
Structured Clinical Interview for the DSM-IV (SCID) was used to assess diagnostic criteria for alcohol abuse and dependence (First et al., 2002). Because most participants met criteria for a lifetime diagnosis of alcohol dependence, our analyses includes a dichotomous indicator scored 1 if the participant met diagnostic criteria for alcohol dependence in the month prior to baseline assessment. Participants were also asked if their mothers and fathers ever had an alcohol problem. We include dichotomous indicators scored 1 if the participant reported that their mother or father ever had an alcohol problem. Other covariates included age in years, and race (1 if Caucasian).

\section{Table 1 about here.}

\section{Results}

Participants averaged 34 years of age and $70.5 \%$ were Caucasian (see Table 1). Participants reported using alcohol on about $47.0 \%$ of the days assessed by the pre-baseline TLFB. On average they consumed $10.47( \pm 8.66$; median $=7.23)$ drinks per drinking day. Most $(86.8 \%)$ met clinical criteria for a lifetime diagnosis of alcohol abuse, $88.9 \%$ met criteria for a lifetime diagnosis of alcohol dependence, and $64.4 \%$ met criteria for a diagnosis of alcohol dependence in the month prior to assessment. Participants reported an average of $6.26( \pm 3.87)$ of the 14 adverse alcohol consequences about which they were asked. Eighty (42.1\%) and $120(63.2 \%)$ said their mother and father, respectively, had ever had an alcohol problem (Table 1).

\section{Table 2 about here.}

Zero-order correlations are given in Table 2. Experiencing adverse drinking consequences was positively and significantly associated with age, mean drinks per drinking day, proportion of 
days using alcohol, and peer alcohol use and support. Participants who said their mother or father ever had alcohol problems and those who met criteria for recent diagnosis of alcohol dependence also reported significantly more adverse drinking consequences. Caucasians reported significantly more adverse drinking consequences than ethnic and racial minorities, but the association was relatively weak. Of particular note is the strong and statistically significant bivariate correlation between selfcontrol and adverse drinking consequences $(\mathrm{r}=-.45)$; as self-control increased, adverse drinking consequences tended to decrease. The association is approximately linear across the range of selfcontrol observed in this sample.

Self-control was also inversely and significantly associated with mean drinks per drinking day and proportion of days participants reported using any alcohol (see Table 2). Participants who said their mother or their father ever had an alcohol problem also scored significantly lower on selfcontrol, as we would expect from self-control theory - to the extent that parenting is an activity that requires self-control, and to the extent that drinking problems are a manifestation of low self-control, we would expect parents with drinking problems to be less effective at teaching their children selfcontrol.

\section{Table 3 about here.}

Table 3 summarizes results for three OLS regression models predicting adverse alcohol consequences. Model 1 is the full model that included all covariates including the indicators of alcohol consumption (frequency, quantity, and the frequency by quantity interaction) and alcohol dependence. Adverse alcohol consequences decreased significantly as self-control increased, increased significantly with age, increased significantly with peer support and use of alcohol, and increased significantly with mean drinks per drinking day. Participants who met criteria for recent 
diagnosis of alcohol dependence reported more adverse drinking consequences, as did those who said their father had ever had a problem with alcohol. The full model accounted for $47 \%$ of the variance in adverse drinking consequences. A comparison of the $\mathrm{R}^{2}$ statistics from model 1 and model 2, which excludes only the index of self-control, indicates that self-control uniquely explained approximately $9 \%$ of the variance in adverse drinking consequences after controlling for background characteristics and indicators of alcohol use behaviors. In model 3, we exclude the four measures intended to represent alcohol consumption and recent alcohol dependence; these 4 measures jointly explain approximately $6 \%$ of the variance in adverse drinking consequences after controlling for all other covariates.

\section{Table 4 about here.}

Additionally, we estimated the adjusted and unadjusted effects of self-control on each of the fourteen individual adverse alcohol consequences (Table 4). After adjusting for all covariates (frequency and quantity of alcohol consumption, alcohol-dependence, peer use and support for alcohol, age, and race) increased self-control was associated with significantly lower odds of eleven of the individual adverse alcohol consequences. These included having money problems, having a car accident, getting into physical fights, having been seriously injured while drinking, injuring others while drinking, losing a job or having employment problems, having problems with physical health, having sexual problems, having serious relationship problems, having an unplanned pregnancy, having parenting problems, and losing custody of children. 


\section{DISCUSSION AND CONCLUSIONS}

While previous research has shown that self-control is a predictor of alcohol use, our results go one step further - they show that self-control is a stronger predictor of adverse alcohol consequences than the joint effect of all included measures of alcohol use and alcohol problem severity. We conclude from our findings that our hypothesis is supported, and that self-control can help explain adverse alcohol consequences over and beyond the direct effects of quantity and frequency of alcohol use, alcohol problem severity, and clinical diagnosis of alcohol dependence. These findings suggest that the focus in the literature on alcohol use itself as the main or only cause of negative alcohol consequences is misguided. As in previous research, however, we find that selfcontrol as measured in this study does not completely account for the relationship between alcohol use and adverse consequences, as the relationship between the use and dependence measures is still significant when controlling for self-control.

Despite the obvious connection between alcohol use and negative consequences such as health problems, our results show that it is useful to conceptualize alcohol abuse and alcohol-related problems in part as common outcomes of low self-control. Those with lower self-control are more likely to use alcohol to excess, but even among heavy alcohol users or those who are alcohol dependent, there is variation in self-control that helps explain the number and severity of adverse drinking consequences. Put differently, those with lower self-control are likely to suffer more from the apparent adverse consequences of alcohol than those with higher self-control. This finding is consistent with that of Gibson, Schreck, and Miller (2004), who found no relationship between binge drinking and alcohol consequences among those with very high self-control. It is also consistent with research focusing on specific alcohol-related self-control techniques. That research shows that those who use various strategies to reduce drinking, such as counting the number of drinks consumed or 
planning to avoid situations where alcohol will be available, are likely to suffer less serious adverse alcohol consequences (Glassman, Werch, and Jobli, 2007; Haines, Barker, and Rice, 2006).

One potential limitation of our research is the issue of time order, because self-control was measured subsequent to the alcohol use measures. Thus, it is possible that respondents' level of selfcontrol was affected by prior alcohol use or abuse. Gottfredson and Hirschi (1990) argue that selfcontrol is stable over time once it is established in early childhood, and if this is the case, time order would not be problematic. Research on the issue of the stability of self-control over time is mixed, with some studies showing that self-control is affected by variables such as the level of social control experienced (Na and Paternoster, 2012), or the experience of being incarcerated (Mitchell and MacKenzie, 2006). Other studies have found that self-control varies over time for a small proportion of the population, but that it is stable for the majority of the population studied (Hay and Forrest, 2006; Higgins et al., 2009; Jennings et al., 2013). The design of the current study does not allow us to examine the possibility that respondents' self-control has been affected by prior alcohol use or their incarceration, so our results should be interpreted with caution.

Limitations aside, our results provide support for Gottfredson and Hirschi's (1990) claim that low self-control is a general tendency that leads to a wide variety of negative consequences. It also provides support for their call for a more holistic approach to the study of various forms of deviance and negative life outcomes. If a wide variety of problems stems from a single underlying cause such as self-control, it is important to study the determinants of the underlying cause to try to provide solutions to these problems.

Junger and Dekovic (2003) note that there is little attention in most scientific literature to the co-occurrence of various risk-taking behaviors, and they offer several explanations for this. Part of the problem may be structural, in that different departments in universities and in governmental 
organizations and granting agencies each study their "own” dependent variables (Junger and Dekovic, 2003). It may also be the case that researchers outside of criminology hesitate to associate "their" dependent variable with crime (Junger and Dekovic, 2003). It is likely that lack of knowledgesharing between disciplines is also due to the sheer volume of research in these related fields - it would seem to be a Herculean task to become well versed in the literature on crime, drug use, alcohol use, gambling, dangerous driving, health problems, and so on. Finally, the tendency to treat certain forms or outcomes of risk-taking behavior as diseases in need of treatment probably also contributes to the lack of crossover between disciplines. The disease model of alcoholism may be useful in removing the stigma of alcoholism and possibly encouraging alcoholics to seek treatment (Parsons, 1951). However, conceptualizing alcoholism as a "dispositional disease" leads to the view that it is an “all-or-none unitary disorder caused solely by hereditary physical abnormalities” (Miller, 1993: 133). Clearly, this view does not imply that alcoholism should be studied with a social science perspective, and would likely lead to treatment programs that are limited in scope and very narrowly focused on drinking itself (Miller, 1993).

Whatever the reasons for the lack of knowledge-sharing across disciplines studying risktaking, reckless, or imprudent behavior, the evidence is mounting that the current scientific approach is seriously flawed. If a wide variety of behaviors is caused by low self-control or any other general variable, it is counterproductive to conceptualize and study them as separate entities requiring unique explanations. Our understanding of crime and related behaviors could be vastly improved with more research focusing on the common causes and consequences of these behaviors.

Of course, and perhaps most importantly, treatment or prevention programs that fail to see the common causes of different behaviors and health, relationship, work-related, and legal problems are unlikely to successfully improve the lives of those they're trying to help. One simple example of this 
is programs on college campuses designed to reduce alcohol consumption among students. Many of these programs focus on trying to educate students on the potential harm that can come from drinking to excess, such as academic failure. By the logic of self-control theory, however, both drinking to excess and poor grades are outcomes of low self-control, implying that students who drink to excess and skip a lot of classes are likely to skip a lot of classes whether they've been drinking or not. Taking this perspective into account might help colleges and universities develop strategies that focus on the root of the problem. Others have similarly advocated a holistic or ecological approach to treatment and prevention (e.g. Reininger et al., 2005), and our results would support such approaches.

Gottfredson and Hirschi (1990) argue that self-control is established in early childhood, and that efforts to instill self-control later in life are unlikely to be successful. However, it's certainly possible to establish programs for young children in schools that are more targeted toward overall levels of self-control than to specific issues such as drinking, drug use, or practicing safe sex. Thus, we see this as one area in which a more holistic approach to reducing risky behavior could be very promising, and such programs would be easily tailored to children of different age groups.

\section{FUNDING}

This research was supported by National Institute on Alcohol Abuse and Alcoholism Grant AA014495 and National Institute on Drug Abuse Mid-Career Award DA000512. Clinical Trial \#NCT00237003 was awarded to Michael D. Stein. 


\section{REFERENCES}

Arneklev, Bruce J., Harold G. Grasmick, Charles R. Tittle and Robert J. Bursik Jr. 1993. "Low SelfControl and Imprudent Behavior." Journal of Quantitative Criminology 9:225-247.

Baker, Joseph O. 2010. "The Expression of Low Self-Control as Problematic Drinking in Adolescents: An Integrated Control Perspective." Journal of Criminal Justice 38:237-244.

Benton, Stephen L., Sherry A. Benton and Ronald G. Downey. 2006. "College Student Drinking, Attitudes Toward Risks, and Drinking Consequences." Journal of Studies on Alcohol and Drugs 67:543.

Botchkovar, Ekaterina V. and Lisa Broidy. 2013. "Parenting, Self-Control, and the Gender Gap in Heavy Drinking the Case of Russia." International Journal of Offender Therapy and Comparative Criminology 57:357-376.

Britt, Chester L. 1994. "Versatility." Pp. 173-191 in The Generality of Deviance, edited by T. Hirschi and M. R. Gottfredson. Transaction Books.

Chapple, Constance L. and Trina L. Hope. 2003. "An Analysis of the Self-Control and Criminal Versatility of Gang and Dating Violence Offenders." Violence and Victims 18:671-690.

Cochran, John K., Peter B. Wood, Christine S. Sellers, Wendy Wilkerson and Mitchell B. Chamlin. 1998. "Academic Dishonesty and Low self-control: An Empirical Test of a General Theory of Crime." Deviant Behavior 19:227-255. 
Costello, Barbara J., Bradley J. Anderson and Michael D. Stein. 2006. "Heavy Episodic Drinking among Adolescents: A Test of Hypotheses Derived from Control Theory." Journal of Alcohol and Drug Education 50:35.

Cox, W. M., Steven G. Hosier, Sophie Crossley, Becky Kendall and Katherine L. Roberts. 2006. "Motives for Drinking, Alcohol Consumption, and Alcohol-Related Problems among British Secondary-School and University Students." Addictive Behaviors 31:2147-2157.

D'Amico, Elizabeth J., Jane Metrik, Denis M. McCarthy, Kevin C. Frissell, Mark Applebaum and Sandra A. Brown. 2001. "Progression into and Out of Binge Drinking among High School Students." Psychology of Addictive Behaviors 15:341.

De Li, Spencer. 2005. "Race, Self-Control, and Drug Problems among Jail Inmates." Journal of Drug Issues 35:645-663.

DeLisi, Matt. 2001. "It's all in the Record: Assessing Self-Control Theory with an Offender Sample." Criminal Justice Review 26:1-16.

DeLisi, Matt, Andy Hochstetler and Daniel S. Murphy. 2003. "Self-Control Behind Bars: A Validation Study of the Grasmick Et Al. Scale." Justice Quarterly 20:241-263.

Evans, T. D., Francis T. Cullen, Velmer S. Burton, R. G. Dunaway and Michael L. Benson. 1997. "The Social Consequences of self-control: Testing the General Theory of Crime*." Criminology $35: 475-504$. 
Eysenck, Sybil B.G., Paul R. Pearson, G. Easting and John F. Allsopp. 1985. "Age Norms for Impulsiveness, Venturesomeness and Empathy in Adults." Personality and Individual Differences 6:613-619.

First, Michael B., Robert L. Spitzer, Miriam Gibbon and Janet B. Williams. 2002. "Structured Clinical Interview for DSM-IV-TR Axis I Disorders, Research Version, Patient Edition." New York: Biometrics Research, New York State Psychiatric Institute.

GENACIS Website. 2014. www.genacis.org. Retrieved February 13, 2014.

Gerich, Joachim. 2013. "The Inhibiting Function of Self-Control and Social Control on Alcohol Consumption." Journal of Drug Issues: 0022042613491110.

Gibbs, John J., and Dennis Giever. 1995. "Self-control and Its Manifestations among University Students: An Empirical Test of Gottfredson and Hirschi's General Theory." Justice Quarterly 12: 231-255.

Gibbs, John J., Dennis Giever and Jamie S. Martin. 1998. "Parental Management and Self-Control: An Empirical Test of Gottfredson and Hirschi's General Theory." Journal of Research in Crime and Delinquency 35:40-70.

Gibson, Chris, Christopher J. Schreck and J. M. Miller. 2004. "Binge Drinking and Negative Alcohol-Related Behaviors: A Test of Self-Control Theory." Journal of Criminal Justice 32:411420.

Glassman, Tavis, Chudley C. Werch and Edessa Jobli. 2007. "Alcohol Self-Control Behaviors of Adolescents." Addictive Behaviors 32:590-597. 
Gottfredson, Michael R. and Travis Hirschi. 1990. A General Theory of Crime. Stanford, CA: Stanford University Press.

Gottfredson, Michael R. and Travis Hirschi. 2003. "A General Theory of Crime." Pp. 240-252 in Criminological Theory: Past to Present: Essential Readings, edited by F.T. Cullen and R. Agnew. Los Angeles: Roxbury Publishing.

Graham, Kathryn, Sharon Bernards, Ronald Knibbe, Sylvia Kairouz, Sandra Kuntsche, Sharon C. Wilsnack, Thomas K. Greenfield, Paul Dietze, Isidore Obot and Gerhard Gmel. 2011. "Alcohol-related Negative Consequences among Drinkers Around the World." Addiction 106:1391-1405.

Grasmick, Harold G., Charles R. Tittle, Robert J. Bursik and Bruce J. Arneklev. 1993. "Testing the Core Empirical Implications of Gottfredson and Hirschi's General Theory of Crime." Journal of Research in Crime and Delinquency 30:5-29.

Gunter, Whitney D. and Nicholas W. Bakken. 2012. "The Many Measurements of Self-Control: How Re-Operationalized Self-Control Compares." European Journal of Criminology 9:309-322.

Haines, Michael P., Gregory Barker and Richard M. Rice. 2006. "The Personal Protective Behaviors of College Student Drinkers: Evidence of Indigenous Protective Norms." Journal of American College Health 55:69-76.

Hay, Carter, and Walter Forrest. 2006. "The development of self-control: Examining self-control theory's stability thesis." Criminology 44:739-774. 
Hay, Carter and Walter Forrest. 2008. "Self-control Theory and the Concept of Opportunity: The Case for a More Systematic Union*." Criminology 46:1039-1072.

Hayaki, Jumi, Bradley Anderson and Michael Stein. 2006. "Sexual Risk Behaviors among Substance Users: Relationship to Impulsivity." Psychology of Addictive Behaviors 20:328.

Hayaki, Jumi, Michael D. Stein, Joanna A. Lassor, Debra S. Herman and Bradley J. Anderson. 2005. "Adversity among Drug Users: Relationship to Impulsivity." Drug and Alcohol Dependence 78:65-71.

Hebert, Megan R., Jennifer G. Clarke, Celeste M. Caviness, Moira K. Ray, Peter D. Friedmann and Michael D. Stein. 2008. "Feasibility of Gaining Access to Women in Jail for Health Interventions." Women \& Health 47:79-93.

Higgins, George E. 2004. "Can Low Self-Control Help with the Understanding of the Software Piracy Problem?" Deviant Behavior 26:1-24.

Higgins, George E., Wesley G. Jennings, Richard Tewksbury, and Chris L. Gibson. 2009. "Exploring the link between low self-control and violent victimization trajectories in adolescents." Criminal Justice and Behavior 36:1070-1084.

Horn, John L. 1965. "A Rationale and Test for the Number of Factors in Factor Analysis." Psychometrika 30:179-185.

Jellinek, Elvin M. 1946. "Phases in the Drinking History of Alcoholics." Quarterly Journal of Studies on Alcohol 7:1-88. 
Jennings, Wesley G., George E. Higgins, Ronald L. Akers, David N. Khey, and Jason Dobrow. 2013. "Examining the influence of delinquent peer association on the stability of self-control in late childhood and early adolescence: Toward an integrated theoretical model.” Deviant Behavior $34: 407-422$.

Jones-Webb, Rhonda, Brian Short, Alexander Wagenaar, Tracie Toomey, David Wolfson, Mark Wolfson and Jean Forster. 1997. "Environmental Predictors of Drinking and Drinking-Related Problems in Young Adults." Journal of Drug Education 27:67-82.

Junger, Marianne and Maja Dekovic. 2003. "Crime as a Risk-Taking: Co-Occurrence of Delinquent Behavior, Health-Endangering Behaviors, and Problem Behaviors." Pp. 213-248 in Advances in Criminological Theory Volume 12: Control Theories of Crime and Delinquency, edited by C.L. Britt and M.R. Gottfredson. Piscataway, NJ: Transaction.

Keane, Carl, Paul S. Maxim and James J. Teevan. 1993. "Drinking and Driving, Self-Control, and Gender: Testing a General Theory of Crime." Journal of Research in Crime and Delinquency $30: 30-46$.

Langton, Lynn, Nicole L. Piquero and Richard C. Hollinger. 2006. "An Empirical Test of the Relationship between Employee Theft and Low Self-Control." Deviant Behavior 27:537-565.

Love, Sharon R. 2006. "Illicit Sexual Behavior: A Test of Self-Control Theory." Deviant Behavior 27:505-536. 
Markman Geisner, Irene, Mary E. Larimer and Clayton Neighbors. 2004. "The Relationship among Alcohol use, Related Problems, and Symptoms of Psychological Distress: Gender as a Moderator in a College Sample." Addictive Behaviors 29:843-848.

McGloin, Jean M., Christopher J. Sullivan and Alex R. Piquero. 2009. "Aggregating to Versatility? Transitions among Offender Types in the Short Term." British Journal of Criminology 49:243264.

Midanik, Lorraine T., Tammy W. Tam, Thomas K. Greenfield and Raul Caetano. 1996. "Risk Functions for alcohol-related Problems in a 1988 US National Sample." Addiction 91:14271437.

Miller, William R. 1993. "Alcoholism: Toward a Better Disease Model." Psychology of Addictive Behaviors 7:129.

Miller, William R., J. S. Tonigan and Richard Longabaugh. 1995. The Drinker Inventory of Consequences (DrInC): An Instrument for Assessing Adverse Consequences of Alcohol Abuse: Test Manual. US Department of Health and Human Services, Public Health Service, National Institutes of Health, National Institute on Alcohol Abuse and Alcoholism.

Mitchell, Ojmarrh, and Doris Layton MacKenzie. 2006. "The Stability and Resiliency of Self-Control in a Sample of Incarcerated Offenders." Crime \& Delinquency 52:432-449.

Na, Chongmin, and Raymond Paternoster. 2012. "Can Self-Control Change Substantially Over Time? Rethinking the Relationship Between Self- and Social Control.” Criminology 50:427-462. 
Nagin, Daniel S. and Raymond Paternoster. 1993. "Enduring Individual Differences and Rational Choice Theories of Crime." Law and Society Review 27:467-496.

National Institute of Alcohol Abuse and Alcoholism. 2004. "NIAAA Council Approves Definition of Binge Drinking." NIAAA Newsletter 3:3.

Osgood, D. W., Lloyd D. Johnston, Patrick M. O'Malley and Jerald G. Bachman. 1988. "The Generality of Deviance in Late Adolescence and Early Adulthood." American Sociological Review 53:81-93.

Pardini, Dustin, Helene R. White and Magda Stouthamer-Loeber. 2007. "Early Adolescent Psychopathology as a Predictor of Alcohol use Disorders by Young Adulthood." Drug and Alcohol Dependence 88:S38-S49.

Parsons, Talcott. 1951. "Illness and the Role of the Physician: A Sociological Perspective*." American Journal of Orthopsychiatry 21:452-460.

Piquero, Alex R. 2008. "Measuring Self-Control." Pp. 26-37 in Out of Control: Assessing the General Theory of Crime, edited by E. Goode. Stanford, CA: Stanford University Press.

Piquero, Alex R., Chris L. Gibson, and Stephen G. Tibbetts. 2002. "Does self-control account for the relationship between binge drinking and alcohol-related behaviours?" Criminal Behaviour and Mental Health 12:135-154.

Piquero, Alex and Stephen Tibbetts. 1996. "Specifying the Direct and Indirect Effects of Low SelfControl and Situational Factors in Offenders' Decision Making: Toward a More Complete Model of Rational Offending." Justice Quarterly 13:481-510. 
Plant, Moira, Patrick Miller, Christine Thornton, Martin Plant and Kim Bloomfield. 2000. "Life Stage, Alcohol Consumption Patterns, Alcohol-Related Consequences, and Gender." Substance Abuse 21:265-281.

Podaná, Zuzana and Jiř́i Buriánek. 2013. "Does Cultural Context Affect the Association between Self-Control and Problematic Alcohol use among Juveniles? A Multilevel Analysis of 25 European Countries." Journal of Contemporary Criminal Justice 29:70-87.

Pratt, Travis C. and Francis T. Cullen. 2000. "The Empirical Status of Gottfredson and Hirschi's General Theory of Crime: A meta-analysis." Criminology 38:931-964.

Ramstedt, Mats. 2002. "Alcohol Consumption and the Experience of Adverse Consequences-A Comparison of Six European Countries." Contemporary Drug Problems 29:549.

Ramstedt, Mats and Ann Hope. 2005. "The Irish Drinking Habits of 2002-Drinking and DrinkingRelated Harm in a European Comparative Perspective." Journal of Substance Use 10:273-283.

Rebellon, Cesar J., Murray A. Straus and Rose Medeiros. 2008. "Self-Control in Global Perspective an Empirical Assessment of Gottfredson and Hirschi's General Theory within and Across 32 National Settings." European Journal of Criminology 5:331-361.

Reininger, Belinda M., Alexandra E. Evans, Sarah F. Griffin, Maureen Sanderson, Murray L. Vincent, Robert F. Valois and Deborah Parra-Medina. 2005. "Predicting Adolescent Risk Behaviors Based on an Ecological Framework and Assets." American Journal of Health Behavior 29:150-161. 
Ribeaud, Denis and Manuel Eisner. 2006. "The 'Drug-Crime Link 'from a Self-Control Perspective an Empirical Test in a Swiss Youth Sample." European Journal of Criminology 3:33-67.

Sobell, Linda C., Sangeeta Agrawal, Helen Annis, Hector Ayala-Velazquez, Leticia Echeverria, Gloria I. Leo, Janusz K. Rybakowski, Christer Sandahl, Bill Saunders and Sally Thomas. 2001. "Cross-Cultural Evaluation of Two Drinking Assessment Instruments: Alcohol Timeline Followback and Inventory of Drinking Situations." Substance use \& Misuse 36:313-331.

Sobell, Linda C. and Mark B. Sobell. 1992. "Timeline Follow-Back." Pp. 41-72 in Measuring Alcohol Consumption: Psychosocial and Biochemical Methods, edited by R.Z. Litten and J.P. Allen. Springer. New York: Humana Press.

Stein, Michael D., Celeste M. Caviness, Bradley J. Anderson, Meg Hebert and Jennifer G. Clarke. 2010. "A Brief Alcohol Intervention for Hazardously Drinking Incarcerated Women." Addiction 105:466-475.

Strong, David R., Celeste Caviness, Brad Anderson, Richard A. Brown and Michael Stein. 2010. "Assessing the Severity of Hazardous Drinking and Related Consequences among Incarcerated Women." Alcoholism: Clinical and Experimental Research 34:907-914.

Turrisi, Rob, Kimberly A. Mallett, Nadine R. Mastroleo and Mary E. Larimer. 2006. "Heavy Drinking in College Students: Who is at Risk and what is being done about it?" The Journal of General Psychology 133:401-420. 
Vazsonyi, Alexander T. and Jennifer M. Crosswhite. 2004. "A Test of Gottfredson and Hirschi's General Theory of Crime in African American Adolescents." Journal of Research in Crime and Delinquency 41:407-432.

Vazsonyi, Alexander T., Lloyd E. Pickering, Marianne Junger and Dick Hessing. 2001. "An Empirical Test of a General Theory of Crime: A Four-Nation Comparative Study of Self-Control and the Prediction of Deviance." Journal of Research in Crime and Delinquency 38:91-131.

Velicer, Wayne F. 1976. "Determining the Number of Components from the Matrix of Partial Correlations." Psychometrika 41:321-327.

Wechsler, Henry and Bernice Wuethrich. 2002. Dying to Drink: Confronting Binge Drinking on College Campuses. Emmaus, PA: Rodale.

Wolfe, Scott E. and George E. Higgins. 2008. "Self-Control and Perceived Behavioral Control: An Examination of College Student Drinking." Applied Psychology in Criminal Justice 4:108-134.

Wyllie, Allan, Jia-Fang Zhang and Sally Casswell. 2000. "Risk Functions for Frequency of alcohol-related Negative Consequences: New Zealand Survey Data." Addiction 95:1821-1832.

Zwick, William R. and Wayne F. Velicer. 1986. "Comparison of Five Rules for Determining the Number of Components to Retain." Psychological Bulletin 99:432. 
Table 1. Sample Characteristics and Descriptive Statistics ( $\mathrm{n}=190)$.

\begin{tabular}{|c|c|c|c|c|c|}
\hline Descriptive Characteristics & $\mathrm{n}(\%)$ & & & & \\
\hline Race (Caucasian) & $134(70.5 \%)$ & & & & \\
\hline Alcohol Dependent (Yes) & $124(65.3 \%)$ & & & & \\
\hline Mother Alc. Problems (Yes) & $80(42.1 \%)$ & & & & \\
\hline \multirow[t]{2}{*}{ Father Alc. Problems (Yes) } & $120(63.2 \%)$ & & & & \\
\hline & Range & Mean $( \pm$ SD) & $\mathbf{P 2 5}$ & P50 & P75 \\
\hline Age & $18-56$ & $33.95( \pm 8.79)$ & 26.00 & 35.00 & 41.00 \\
\hline Proportion Days Used Alcohol & $0-1$ & $0.49( \pm 0.33)$ & 0.22 & 0.42 & 0.83 \\
\hline Mean Drinks / Drinking Day & $0-60$ & $10.94( \pm 8.70)$ & 4.89 & 8.13 & 14.00 \\
\hline Peer Alcohol Use / Support & $0-12$ & $4.96( \pm 3.58)$ & 2.00 & 5.00 & 8.00 \\
\hline Self-Control & $19-72$ & $45.13( \pm 11.42)$ & 37.00 & 45.00 & 53.00 \\
\hline Adverse Alcohol Consequences & $0-14$ & $6.54( \pm 3.88)$ & 3.00 & 6.00 & 10.00 \\
\hline
\end{tabular}


Table 2. Zero-Order Correlations $(\mathrm{n}=190)$.

\begin{tabular}{|c|c|c|c|c|c|c|c|c|c|}
\hline Variable & 1. & 2. & 3. & 4. & 5. & 6. & 7. & 8. & 9. \\
\hline \multicolumn{10}{|l|}{ 1. Adverse Alc. Consequences } \\
\hline 2. Age & $.30 * *$ & & & & & & & & \\
\hline 3. Race (Caucasian) & $.16^{*}$ & .00 & & & & & & & \\
\hline 4. Mother Alcohol. Problem (Yes) & $.21 *$ & .14 & .01 & & & & & & \\
\hline 5. Father Alcohol Problem (Yes) & $.24 * *$ & .01 & .08 & $.14^{*}$ & & & & & \\
\hline 6. Mean Drinks / Drinking Day & $.28 * *$ & -.10 & -.07 & .11 & .06 & & & & \\
\hline 7. Proportion Days Used Alcohol & $.24 * *$ & .01 & -.04 & .10 & .11 & $.22 * *$ & & & \\
\hline 8. Alcohol Dependent (Yes) & $.34 * *$ & .07 & .04 & -.00 & .08 & $.29 * *$ & $.38 * *$ & & \\
\hline 9. Peer Alcohol Use / Support & $.38 * *$ & .05 & -.01 & $.21 * *$ & $.15 *$ & $.16^{*}$ & $.25 * *$ & $.28 * *$ & \\
\hline 10. Self-Control & $-.45 * *$ & .10 & -.04 & $-.17 *$ & $-.15^{*}$ & $-.28 * *$ & $-.17 *$ & $-.20 * *$ & $-.32 * *$ \\
\hline
\end{tabular}

$* \mathrm{p}<.05, * * \mathrm{p}<.01$ 
Table 3. Least Squares Regression Models Predicting Adverse Alcohol Consequences $(\mathrm{n}=190)$.

\begin{tabular}{|c|c|c|c|}
\hline Predictor & Model 1 & Model 2 & Model 3 \\
\hline Self Control & $\begin{array}{c}-.331 * * \\
(.058)\end{array}$ & & $\begin{array}{c}-.388 * * \\
(.055)\end{array}$ \\
\hline Age & $\begin{array}{l}.324 * * \\
(.058)\end{array}$ & $\begin{array}{l}.285^{* * *} \\
(.060)\end{array}$ & $\begin{array}{l}.324 * * \\
(.060)\end{array}$ \\
\hline Race (Caucasian) & $\begin{array}{l}.316^{*} \\
(.126)\end{array}$ & $\begin{array}{l}.359 * * \\
(.132)\end{array}$ & $\begin{array}{l}.295^{*} \\
(.127)\end{array}$ \\
\hline Mother Alcohol Problem (Yes) & $\begin{array}{l}.064 \\
(.123)\end{array}$ & $\begin{array}{l}.134 \\
(.133)\end{array}$ & $\begin{array}{l}.056 \\
(.125)\end{array}$ \\
\hline Father Alcohol Problem (Yes) & $\begin{array}{l}.257 * \\
(.114)\end{array}$ & $\begin{array}{l}.311^{*} \\
(.123)\end{array}$ & $\begin{array}{l}.276^{*} \\
(.117)\end{array}$ \\
\hline Peer Alcohol Use/Support & $\begin{array}{l}.162 * \\
(.062)\end{array}$ & $\begin{array}{l}.241^{* *} \\
(.066)\end{array}$ & $\begin{array}{l}.215^{* * *} \\
(.061)\end{array}$ \\
\hline Alcohol Dependent (Yes) & $\begin{array}{l}.284 * \\
(.134)\end{array}$ & $\begin{array}{l}.332 * \\
(.137)\end{array}$ & \\
\hline Prop. Days Using Alcohol & $\begin{array}{c}.041 \\
(.054)\end{array}$ & $\begin{array}{c}.048 \\
(.060)\end{array}$ & \\
\hline Mean Drinks / Drinking Day & $\begin{array}{l}.145 * * \\
(.055)\end{array}$ & $\begin{array}{l}.208 * * \\
(.065)\end{array}$ & \\
\hline Quantity by Freq. Interaction & $\begin{array}{l}-.003 \\
(.052)\end{array}$ & $\begin{array}{c}.027 \\
(.058)\end{array}$ & \\
\hline Constant & $\begin{array}{c}-.597 * * \\
(.142)\end{array}$ & $\begin{array}{c}-.728 * * \\
(.146)\end{array}$ & $\begin{array}{c}-.406 * * \\
(.124)\end{array}$ \\
\hline Model R-squared & .47 & .38 & .41 \\
\hline
\end{tabular}

Robust standard errors in parentheses

$* * \mathrm{p}<0.01, * \mathrm{p}<0.05$ 
Table 4. Unadjusted and Adjusted Effects of Self-Control on the Odds of Fourteen Specific Adverse Alcohol Consequences $(\mathrm{n}=190)$.

\begin{tabular}{|c|c|c|c|c|}
\hline \multirow[b]{2}{*}{ Item } & \multicolumn{2}{|c|}{ Unadjusted } & \multicolumn{2}{|c|}{ Adjusted $^{\mathrm{a}}$} \\
\hline & $\mathbf{O R}^{\mathbf{b}}$ & $95 \% \mathrm{CI}$ & $\mathbf{O R}^{\mathbf{b}}$ & $95 \% \mathrm{CI}$ \\
\hline $\begin{array}{l}\text { Have you ever had money problems like not being } \\
\text { able to afford food or pay bills/rent because of your } \\
\text { drinking? }\end{array}$ & $.39 * * *$ & $.26-.57$ & $.36 * * *$ & $.21-.60$ \\
\hline $\begin{array}{l}\text { Have you ever had a car accident while you were } \\
\text { drinking or under the influence of alcohol? }\end{array}$ & $.59 * * *$ & $.44-.80$ & $.64 * *$ & $.45-.90$ \\
\hline $\begin{array}{l}\text { Have you ever gotten into a physical fight while } \\
\text { you were drinking or under the influence of } \\
\text { alcohol? }\end{array}$ & $.53 * * *$ & $.37-.75$ & $.63 *$ & $.40-.99$ \\
\hline $\begin{array}{l}\text { Have you ever been arrested because you were } \\
\text { drinking or under the influence of alcohol? }\end{array}$ & $.74 *$ & $.56-.99$ & .77 & $.53-1.12$ \\
\hline $\begin{array}{l}\text { Have you ever been seriously injured while you } \\
\text { were drinking or under the influence of alcohol? }\end{array}$ & $.61 * *$ & $.45-.83$ & $.67 *$ & $.47-.95$ \\
\hline $\begin{array}{l}\text { Have you ever injured someone else while you } \\
\text { were drinking or under the influence of alcohol? }\end{array}$ & $.55^{* * *}$ & $.40-.74$ & $.65^{*}$ & $.46-.91$ \\
\hline $\begin{array}{l}\text { Have you ever lost a job or had to leave school } \\
\text { because of drinking alcohol? }\end{array}$ & $.45^{* * *}$ & $.32-.66$ & $.45^{* * * *}$ & $.31-.66$ \\
\hline $\begin{array}{l}\text { Has your drinking ever caused physical health } \\
\text { problems? }\end{array}$ & $.61 * *$ & $.43-.83$ & $.67 *$ & $.46-.98$ \\
\hline $\begin{array}{l}\text { Has your drinking ever caused problems in your } \\
\text { sex life? }\end{array}$ & $.68 *$ & $.49-.96$ & $.63 *$ & $.43-.94$ \\
\hline $\begin{array}{l}\text { Has a serious relationship (such as a marriage) ever } \\
\text { ended because of your drinking? }\end{array}$ & $.51 * * *$ & $.36-.73$ & $.52 * *$ & $.34-.77$ \\
\hline $\begin{array}{l}\text { Has your drinking ever damaged your relationship } \\
\text { with your family? }\end{array}$ & $.63 * *$ & $.46-.86$ & .70 & $.48-1.00$ \\
\hline $\begin{array}{l}\text { Have you ever had an unplanned pregnancy that } \\
\text { occurred because you were drinking or under the } \\
\text { influence of alcohol? }\end{array}$ & $.60 * *$ & $.42-.84$ & $.52 * *$ & $.32-.82$ \\
\hline $\begin{array}{l}\text { Has your drinking ever caused a problem for you } \\
\text { as a parent (such as not paying attention to } \\
\text { children, forgetting about them, etc.)? }\end{array}$ & $.47 * * *$ & $.33-.65$ & $.45^{* * * *}$ & $.31-.66$ \\
\hline $\begin{array}{l}\text { Have you ever lost custody of your children, even } \\
\text { just for a day or two, because of your drinking? }\end{array}$ & $.50 * * *$ & $.34-.72$ & $.62 *$ & $.40-.96$ \\
\hline
\end{tabular}

$* \mathrm{p} \leq .05, * * \mathrm{p} \leq .01, * * * \mathrm{p} \leq .001$. $\mathrm{P}$ values and confidence interval estimates based on robust standard error estimators.

a Adjusted for age, race, mother had an alcohol problem, father had an alcohol problem, others' use

and support of alcohol, alcohol dependence, proportion of days using alcohol, mean drinks / drinking day, and the quantity by frequency interaction.

b Self-control was standardized to zero mean and unit variance prior to estimating the effects. The coefficients give the estimated effect of a 1 standard deviation (11.42 unit) increase in selfcontrol on the odds of each adverse consequence. 
Appendix 1. Self-Control Items and Factor Loadings.

\begin{tabular}{|c|c|c|}
\hline \multirow[b]{2}{*}{ Items } & \multicolumn{2}{|c|}{ Factor Loadings } \\
\hline & Initial $^{\mathrm{a}}$ & Index ${ }^{\mathrm{b}}$ \\
\hline 1. I often act on the spur of the moment. & .42 & .41 \\
\hline 2. I frequently try to avoid things I know will be difficult. & .27 & deleted $^{\mathrm{c}}$ \\
\hline $\begin{array}{l}\text { 3. I like to test myself every now and then by doing something a little } \\
\text { risky. }\end{array}$ & .53 & .55 \\
\hline $\begin{array}{l}\text { 4. If I had a choice, I would almost always rather do something } \\
\text { physical than something mental. }\end{array}$ & .30 & deleted \\
\hline $\begin{array}{l}\text { 5. I try to look out for myself first, even if it means making things } \\
\text { difficult for other people. }\end{array}$ & .43 & .41 \\
\hline 6. I lose my temper pretty easily. & .52 & .53 \\
\hline 7. I don't devote much thought and effort to preparing for the future. & 65 & 66 \\
\hline 8. When things get complicated, I tend to quit or withdraw. & .53 & .55 \\
\hline 9. Sometimes I will take a risk just for the fun of it. & .65 & .66 \\
\hline $\begin{array}{l}\text { 10. I almost always feel better when I am on the move than when I } \\
\text { am sitting and thinking. }\end{array}$ & .23 & deleted \\
\hline $\begin{array}{l}\text { 11. I'm not very sympathetic to other people when they are having } \\
\text { problems. }\end{array}$ & .28 & deleted \\
\hline $\begin{array}{l}\text { 12. Often, when I'm angry at people, I feel more like hurting them } \\
\text { than talking to them about why I'm angry. }\end{array}$ & .55 & .56 \\
\hline $\begin{array}{l}\text { 13. I often do whatever brings me pleasure here and now, even at the } \\
\text { cost of future goals. }\end{array}$ & .74 & .75 \\
\hline $\begin{array}{l}\text { 14. The things in life that are the easiest to do bring me the most } \\
\text { pleasure. }\end{array}$ & .56 & .55 \\
\hline $\begin{array}{l}\text { 15. I sometimes find it exciting to do things for which I might get in } \\
\text { trouble. }\end{array}$ & .63 & 64 \\
\hline $\begin{array}{l}\text { 16. I like to get out and do things more than I like to read or } \\
\text { contemplate ideas. }\end{array}$ & .34 & deleted \\
\hline 17. If things I do upset other people, it's their problem, not mine. & 60 & .59 \\
\hline 18. When I am really angry, other people better stay away from me. & .54 & .55 \\
\hline $\begin{array}{l}\text { 19. I am more concerned with what happens to me in the short run } \\
\text { than in the long run. }\end{array}$ & .67 & .67 \\
\hline 20. I dislike really hard tasks that stretch my abilities to the limit. & .53 & .51 \\
\hline 21. Excitement and adventure are more important to me than security. & .55 & .55 \\
\hline $\begin{array}{l}\text { 22. I seem to have more energy and greater need for activity than } \\
\text { most other people my age. }\end{array}$ & .09 & deleted \\
\hline $\begin{array}{l}\text { 23. I will try to get the things I want even when I know it's causing } \\
\text { problems for other people. }\end{array}$ & .71 & .73 \\
\hline $\begin{array}{l}\text { 24. When I have a serious disagreement with someone, it's usually } \\
\text { hard for me to talk about it without getting upset. }\end{array}$ & .43 & .43 \\
\hline
\end{tabular}

\footnotetext{
${ }^{a}$ Loadings of all 24 items on a single principal component.

${ }^{b}$ Loadings of the 18 items included in the final self-control index.

${ }^{\mathrm{c}}$ Items not included in the final self-control index.
} 


\section{Biographical Sketches:}

Barbara J. Costello is Associate Professor of Sociology at the University of Rhode Island. Her research is focused on the development and testing of control theories of crime, the application of control theory to dependent variables outside of the traditional realm of criminology, and on the mechanisms of peer influence on behavior.

Bradley Anderson, $\mathrm{PhD}$, is a Senior Research Methodologist in the General Medicine Research Unit at Butler Hospital in Providence, RI. His interests include substance abuse and harm reduction in high risk populations. Current projects include randomized clinical trials involving substance abuse and sexual risk taking in emerging adults, smoking reduction in methadone patients, and linking hospitalized opioid dependent patients to treatment.

Dr. Michael Stein is Professor of Medicine, Health Services, Policy \& Practice at Brown University. An internist based at Butler Hospital in Providence, he is an internationally known HIV and substance abuse researcher, having served as PI of more than $20 \mathrm{NIH}$-funded projects. Dr. Stein's interests span populations, substances (opioids, marijuana, alcohol, cigarettes), and outcomes (relapse prevention, medication adherence, medical and substance use complications, sleep, HIV/STI risk). His work with incarcerated women dates back a decade. 